\title{
Befindlichkeit e Stimmung: Os afetos na analítica existencial de Martin Heidegger
}

\section{Befindlichkeit and Stimmung: The affections in the existential analytic of Martin Heidegger}

\author{
GIOVANI AUGUSTO DOS SANTOS
}

Resumo: A questão sobre o ser sempre acompanhou Heidegger em todos seus caminhos filosóficos. À luz desse projeto principal, outros temas ganharam a atenção do filósofo à medida que servem a pensar o ser. Um desses temas é o afeto, tema do presente trabalho. Ao falar sobre afetos, Heidegger utiliza dois termos, a saber Befindlichkeit e Stimmung. Nesse sentido, o objetivo deste trabalho é analisar esses fenômenos, especificamente na analítica existencial do ser-aí. Encontra-se no início do \$29 de Ser e tempo a seguinte indicação: "O que indicamos ontologicamente com o termo disposição [Befindlichkeit] é, onticamente, o mais conhecido e o mais cotidiano, a saber, o humor [die Stimmung], o estar afinado num humor [das Gestimmtsein]". Nesse sentido pode-se questionar: o que o autor quer indicar com os termos Befindlichkeit e Stimmung? Os termos disposição e humor traduzem precisamente esses fenômenos? Existem outras palavras que melhor traduzam? Para além da tradução, como compreender a Befindlichkeit e a Stimmung? São eles dois fenômenos ou um único? Tentando pensar essas questões, será utilizado uma revisão narrativa de literatura, especificamente de Ser e tempo e de tradutores e comentadores da obra heideggeriana, indicando que, embora sejam fenômenos de difícil tradução é possível pensar de maneira mais afinada com Heidegger dependendo do termo utilizado para traduzir alguns de seus termos ao português. Também será possível compreender que, embora dois fenômenos, Befindlichkeit e Stimmung são fenômenos correlatos ônticoontológico. E, ainda que de maneira provisória, ter-se-á uma visão do papel que os afetos assumem na economia, não só da ontologia fundamental, mas do próprio exercício do pensamento na obra heideggeriana.

Palavras-chave: Befindlichkeit; Stimmung. Afetos. Analítica existencial. Heidegger.

Abstract: The question of being has always accompanied Heidegger in all his philosophical ways. In the light of this main project, other themes have gained the attention of the philosopher as they serve to think the being. One of these themes is affection, the theme of this work. When speaking about affections, Heidegger uses two terms, namely Befindlichkeit and Stimmung. In this sense, the objective of this work is to analyze these phenomena, specifically in the existential analytic of being-there. It is found at the beginning of $\$ 29$ of Being and Time the following statement: "What we indicate ontologically with the term disposition [Befindlichkeit] is, on the one hand, the best known and the most everyday, namely humor [die Stimmung] to be tuned in [Gestimmtsein] mood. " In this sense one can question: what does the author mean by the terms Befindlichkeit and Stimmung? Do the terms mood and mood translate precisely these phenomena? Are there other words that translate better? Beyond Translation, how to understand Befindlichkeit and Stimmung? Are they two phenomena or a single one? Trying to think about these questions, we will use a narrative revision of literature, specifically of Being and time and of translators and commentators of the Heideggerian work, indicating that, although they are difficult to translate phenomena, it is possible to think more closely with Heidegger depending on the term used for translate some of its terms into Portuguese. It will also be

\footnotetext{
${ }^{1}$ Graduado em Psicologia, pelo Centro Universitário FAAT. Mestrando em Filosofia pela UNIOESTE. E-mail: santos.gio@live.com.
} 
possible to understand that although two phenomena, Befindlichkeit and Stimmung are ontological-ontological correlated phenomena. And, although in a provisional way, one will have a vision of the role that the affections assume in the economy, not only of the fundamental ontology, but of the own exercise of the thought in the Heideggerian work.

Keywords: Befindlichkeit; Stimmung. Affections. Existential analytical. Heidegger.

\section{Considerações iniciais}

O projeto filosófico que perpassa toda a obra de Heidegger é o resgate da questão do sentido do ser que estava presente na aurora do pensamento ocidental, mas é esquecida e negligenciada por toda a história da filosofia a partir de Platão e Aristóteles (CASANOVA, 2015). É nesse caminho que surge a obra Ser e tempo, que teve por tarefa construir uma ontologia fundamental que, tendo como ponto de partida a analítica existencial, resgatasse a questão do ser. Nesse sentido, podemos nos questionar: qual o interesse de Heidegger, filosofo do ser, em relação aos afetos?

Os afetos se fazem presentes em todo o percurso filosófico heideggeriano, e aparecem em textos do início da década de 1920, como por exemplo no curso do semestre de verão de 1921, intitulado Agostinho e o neoplatonismo ${ }^{2}$, e continuam em obras posteriores a Ser e tempo, como por exemplo nas Contribuições à filosofia ${ }^{3}$, obra escrita entre os anos de 1936 à 1938 e é tematizado, em 1966, em um dos Seminários de Zollikon ${ }^{4}$, além de diversas outras obras, aulas, cursos, preleções e seminário.

Neste trabalho, nos deteremos especificamente a análise feita por Heidegger no §29 de Ser e tempo, intitulado O ser-aí como disposição (Das Da-sein als Befindlichkeit), no qual Heidegger apresenta o afeto como uma estrutura constitutiva do ser-aí, ou seja, como um existencial. Para além de uma simples síntese do parágrafo e para aquém de estancar toda a riqueza da questão dos afetos presentes no projeto da ontologia fundamental, este trabalho tem por tarefa compreender dois termos utilizados por Heidegger, a saber, Befindlichkeit e Stimmung. Isso se deve ao fato de que não é possível falar de afeto na analítica existencial do ser-aí sem recair, primeiramente, nesses dois fenômenos.

\section{Befindlichkeit, Stimmung e Gestimmtsein}

\footnotetext{
${ }^{2}$ Cf. HEIDEGGER, M. Fenomenologia da vida religiosa. Tradução de Enio Paulo Giachini, Jairo Ferrandin e Renato Kirchner. Petrópolis, RJ: Vozes; Bragança Paulista, SP: Editora Universitária São Francisco, 2010.

${ }^{3}$ Cf. HEIDEGGER, M. Contribuições à filosofia: do acontecimento apropriador. Tradução de Marco Antonio Casanova. Rio de Janeiro: Via Verita, 2014.

${ }^{4}$ Cf. HEIDEGGER, M. BOSS, M. (ed.). Seminários de Zollikon. Tradução de Gabriela Arnhold e Maria de Fátima de Almeida Prado. São Paulo: EDUC; Petrópolis, RJ: Vozes, 2001.
} 
Observa Heidegger (2015, p. 193) que, "O que indicamos ontologicamente com o termo disposição [Befindlichkeit] é, onticamente, o mais conhecido e o mais cotidiano, a saber, o humor [die Stimmung], o estar afinado num humor [das Gestimmtsein]", logo na primeira frase do parágrafo em que apresenta a afetividade em Ser e tempo, como dito anteriormente, §29.

As palavras Befindlichkeit e Stimmung são de difícil tradução para o português, pois não se encontram palavras que guardem os mesmos sentidos empregados por Heidegger. As dificuldades encontradas na tradução desses termos para nossa língua também são encontradas para traduções em outras línguas, mesmo de origem germânica, conforme apontam Elpidorou e Freeman (2015) não existe na língua inglesa, que possui sua origem muito próxima à língua alemã, palavras que sustentem, semanticamente e filosoficamente, o sentido proposto por Heidegger com os termos acima mencionados.

Macquarrie e Robinson ${ }^{5}$, na tradução de Ser e tempo para o inglês, traduzem Befindlichkeit e Stimmung, respectivamente por: "state-of-mind" e mood. Em nota, os tradutores apontam que as escolhas feitas implicam a perda de alguns sentidos das palavras em alemão, mas optam por essas por não haver palavras que melhor descrevam tais fenômenos.

Greisch (1994) também destaca a dificuldade da tradução destes termos para o francês, apontando que não existe correspondente literal para Stimmung nessa língua, sendo comumente traduzido por humeur, citando Michael Haar ele nos diz que: "para traduzir verdadeiramente Stimmung... dever-se-ia poder de algum modo adicionar, em uma só palavra, ressonância, tom, ambiente, tonalidade afetiva subjetiva e objetiva - o que é evidentemente impossível." (GREISCH, 1994, p. $176^{6}$ ). Já Befindlichkeit, que foi traduzido ao francês por Vezin como disposibilité, poderia ser melhor traduzido, ainda segundo Greisch (1994), por affection.

A tradutora Márcia Sá Cavalcante, primeira a traduzir por completo Ser e tempo no Brasil, utiliza a palavra "disposição" para traduzir Befindlichkeit e "humor" para traduzir Stimmung. Já Fausto Castilho, em sua edição bilíngue da mesma obra, traduz Befindlichkeit por "encontrar-se" e Stimmung por "estado-de-ânimo". Ambos os tradutores brasileiros optam por manter a tradição das traduções das línguas neolatinas, como visto em francês disposibilitê e humeur e em espanhol, na tradução de José Gaos, encontrarse e temple.

O que o autor, porém, quer indicar com os termos Befindlichkeit e Stimmung? Os termos disposição ou encontrar-se e humor ou estado-de-ânimo traduzem precisamente esses fenômenos? Existem outras palavras que melhor traduzam? Para

\footnotetext{
${ }_{6}^{5}$ Cf. Heidegger (1962), p. 172, notas dos tradutores 2 e 3.

6 “[...] pour traduire véritavlement Stimmung... il faudrait pouvoir em quelque sorte additionner en um seul mot: vocation, résonance, ton, ambience, accord affetif subjectif et objectif - ce qui est évidemment impossible".
} 
além da tradução, como compreender a Befindlichkeit e a Stimmung? São eles dois fenômenos ou um único?

Com o termo Befindlichkeit, Heidegger indica, ontologicamente, o "como" o ser-aí se encontra ou está em seu aí. A própria palavra utilizada pelo filósofo em alemão deixa isso muito claro, pois, befinden remete-se a como alguém está, acha-se ou encontra-se, como por exemplo à um estado de saúde, ou quando diz sentir-se "bem", "mal", "feliz" ou "triste"; por sua vez, befindlich, tem o sentido de estar situado, de onde ou como alguém se encontra em algum lugar, nesse sentido se trata de uma afecção que perpassa a existência, não se restringindo unicamente a um estar locativo ou subjetivo (INWOOD, 2002).

Irene Borges-Duarte (2015), professora, tradutora e comentadora portuguesa de Heidegger, diz que o filósofo alemão encontra em Agostinho de Hipona o significado do conceito de abertura afetiva da experiência da vida fática marcada pelas affectiones. Esse contato com a filosofia agostiniana já se faz presente no pensamento heideggeriano em 1921, nas lições do semestre de verão daquele ano, anteriormente citada, Agostinho e o neoplatonismo.

A experiência fáctica da vida está marcada pelas affectiones, em ambas as suas modalidades de doação (actual ou memória). Heidegger, lendo Agostinho em 1921, traduz: Affektion, se se trata duma afecção corporal, por ex., uma dor física; Affekt, se não se trata meramente da impressão sensorial, mas da repercussão íntima das impressões num «estado de alma» [seelisches Zustand], implicando consciência e memória - por ex., o estar alegre ou o estar triste ou o recear (BORGES-DUARTE, 2015, p. 4).

Ainda a autora aponta que é em 1924, na conferência $O$ conceito de tempo ${ }^{7}$, novamente para traduzir as affectiones de Agostinho, que Heidegger utiliza pela primeira vez o termo Befindlichkeit, para designar, daí em diante, a abertura afetiva, estrutura fundamental do ser-aí. Por ser utilizado para traduzir para o alemão as affectiones de Agostinho e por guardar em sua origem um estar situado que é passional e ao mesmo tempo locativo, acreditamos, que Befindlichkeit pode ser traduzido, adeaquadamente, para o português por disposição afetiva, afeto ou afetividade.

Já Stimmung vem da palavra Stimme, que significa voz e quer dizer muito mais que apenas humor ou estado-de-ânimo. Stimmung quer dizer afinação, entonação. Apoiados na tradução de diversas obras feitas pelo professor Marco Casanova, como por exemplo Conceitos fundamentais da metafísica: mundo finitude e solidão, Nietzsche I e II e Contribuições à filosofia, destacamos que:

\footnotetext{
${ }^{7}$ Cf. HEIDEGGER, M. O conceito de tempo. Tradução de Irene Borges-Duarte. 2. ed. Lisboa: Fim do Século, 2008. (Edição bilíngue português-alemão).
} 
Algumas são as possibilidades correntes de tradução de Stimmung para o português: disposição, afeto, páthos, disposição de humor etc. Todas estas possibilidades carregam consigo um inevitável peso psicologizante e tendem a inserir no texto um conjunto de significados, do qual justamente Heidegger pretende escapar. Por isto, nós optamos neste contexto de tradução por tonalidade afetiva. Stimmung possui uma relação direta com o vocábulo Stimme, que pode ser traduzido sem mais por 'voz', e com o verbo stimmen, que é utilizado corriqueiramente em linguagem musical para descrever o processo de afinação de um instrumento (CASANOVA, 2011 p. 6 N.T. 2).

Justamente pela indicação de que humor e estado de alma podem causar confusão com termos psicológicos, além de carregarem consigo grande carga metafísica remetendo a interioridade de um sujeito, optamos por tonalidade ou afinação afetiva. Dizer isso é dizer que o ser-aí existe sempre afinado ou em sintonia com um tom, como aponta Koecher (2013), assim como a música é tocada sempre em um tom - mesmo que existam diversos tons não existe música sem tom - a tonalidade afetiva é o que dá tom a existência, como uma sintonia, por vezes desarmônica, que envolve o ser-aí, contrapondo-se a ideia de subjetividade e de estados psíquicos.

Nesse sentido, Xolocotzi (2015) diz que ao se ao falar de afetividade em Heidegger não é possível separar a Befindlichkeit da Stimmung, uma vez que, fundamentados na diferença ontológica, são correlatos ôntico-ontológico, existencial-existenciário:

Da mesma forma que existe uma diferença ontológica entre compreensão e possibilidade, também a disposição afetiva [Befindlichkeit] é ontologicamente diferente da afinação [Stimmung]. Embora a afinação seja algo diferente de disposição, seu caráter de ser é disposicional. Assim como o ente é, a afinação dispõe. A disposição afetiva não é outra coisa senão o caráter ontológico da afinação. E vice-versa, a afinação não é outra coisa senão o caráter ôntico da disposição afetiva. Desse modo, a afinação é sempre afetivamente disposicional e a disposição é sempre afinada. Assim como não há ser sem ente ou ente sem ser, também não há afinação sem disposição ou disposição sem afinação. Contudo, a diferença é mantida e, como o ser não se esgota no ente, a disposição não se extingue na afinação (XOLOCOTZI, 2015, p. 13) ${ }^{8}$.

\footnotetext{
8 "De la misma forma en que hay uma diferencia ontológica entre compreensión y posibilidad, así la disposioción afectiva [Befindlichkeit] es pues ontológicamente diferente al temple [Stimmung]. A pesar de que el temple es algo diferente a la disposición, su carácter de ser es disposicional. Así como el ente es, así el templo dispone. Lo afectivamente disposicional no es outra cosa que el carácter ontológico del temple. Y vice-versa, el temple no es outra cosa que el carácter óntico de la disposición afectiva. De esta forma, el temple es siempre afectivamente disposicional y la disposición es siempre templata. Así como no hay ser sin ente ni ente sin ser, así no hay temple sin disposioción
} 
Elpidorou e Freeman (2015, p.663-664 ${ }^{9}$ ) dizem, de maneira mais simples que:

Os termos "Befindlichkeit" e "Stimmung", portanto, designam um e o mesmo fenômeno, cada um, no entanto, significando isso de uma maneira diferente. Como uma estrutura ontológica da existência do ser-aí, Befindlichkeit é um modo básico de existência e abertura para o mundo. Como a manifestação ôntica de Befindlichkeit, Stimmungen são as várias e específicas maneiras pelas quais o ser-aí pode se relacionar e descerrar o mundo, todas as quais ocorrem contra o pano de fundo da estrutura de Befindlichkeit. Na medida em que Befindlichkeit pertence à estrutura da existência do ser-aí e na medida em que sempre se manifesta através da tonalidade afetiva.

Casanova (2017, p. 158) corrobora também para essa interpretação ao dizer que:

[...] nós já sempre nos encontramos de um modo específico no mundo, e, com isto, a disposição (Befindlichkeit) não é um traço contingente de nosso ser, mas um existencial, uma das estruturas transcendentais que determinam o modo do dar-se do fenômeno ser-aí; é esse modo específico de estar no mundo, que sempre assume onticamente o caráter de uma afinação, de uma atmosfera ou de uma tonalidade afetiva específica (Stimmung), que caracteriza como nós somos quem somos sendo concomitantemente o aí que é o nosso.

É nesse sentido que Heidegger compreende o afeto de uma maneira diferente a como a tradição compreende. Para o filósofo da floresta negra, o afeto não está mais condicionado a uma subjetividade de um sujeito em contraposição a objetividade do objeto. Ele supera a dualidade cartesiana até então fundamento da filosofia e ciência moderna e passa a compreender o afeto como existencial fundamental, antes de qualquer tipo de psicologia:

O âmbito dos afectos alcança, assim, no pensamento de Heidegger, uma dimensão central. Não só se ultrapassa e vence o paradigma moderno da racionalidade, que só permitia ver o emotivo e passional como o que se lhe escapava e se lhe opunha, como, além disso, a afectividade, em íntima e originária articulação com o compreender, se converte numa das estruturas do ser na sua fenomenologia no mundo e linguagem humanos e, nessa medida,

ni disposición sin temple. Sin embargo, la diferencia se mantiene y, así como el ser no se agota em el ente, la disposición no se extingue em el temple".

9 "The terms 'Befindlichkeit' and 'Stimmung' hence designate one and the same phenomenon, each, however, signifying it in a different way. As an ontological structure of Dasein's existence, Befindlichkeit is a basic mode of existence in, and openness to, the world. As the ontic manifestation of Befindlichkeit, Stimmungen are the various and specific ways in which Dasein can relate to and disclose the world, all of which occur against the backdrop of the structure of Befindlichkeit. Insofar as Befindlichkeit belongs to the structure of Dasein's existence and insofar as it is always manifested through mood [...]". 
numa das características ontológicas do próprio ente, que como Dasein, "leva o ser no seu ser" (BORGES-DUARTE, 2015, p. 6).

O afeto, portanto, é uma estrutura ontológica que constitui abertura de mundo, ou seja, diz respeito ao ser, mas se manifesta de forma mais cotidiana através das tonalidades afetivas específicas, que são concretizações ônticas do afeto que perpassa o ser-aí, assim explicita-se como a abertura ontológica dos afetos não é, de forma alguma, um estado psíquico ou de alma, pois, o pensar, o agir e o não agir só podem acontecer em meio a afinação afetiva. É por meio da disposição afetiva que, para Heidegger (2015), se dá a abertura original ao mundo, em outras palavras, o ser-aí não pode acessar ou conhecer o mundo primeiramente por uma faculdade intelectiva, mas "está", desde seu fundamento, em meio à totalidade do ente. E este "estar" é, justamente, o afinar-se afetivamente.

\section{Considerações finais}

Antes de terminarmos algumas coisas são dignas de notas: a primeira é que nesta breve apresentação analisamos apenas uma frase do \$29 de Ser e tempo, parágrafo este central para a compreensão de toda a obra, por isso não pudemos dar conta dos desdobramentos feitos por Heidegger, como, por exemplo, a abertura original dos afetos, a facticidade, a responsabilidade, a liberdade, o estar-lançado, entre outras. Portanto, para uma melhor compreensão sobre o papel fundamental dos afetos na analítica existencial, faz-se necessário uma leitura completa do parágrafo, bem como sua leitura no contexto geral de Ser e tempo.

A segunda coisa a ser ressaltada pode ser colocada através de um famoso jogo de palavras italiano que diz: traduttore, traditore, que significa literalmente tradutor, traidor. Não queremos com esse trocadilho denegrir a imagem do tradutor, muito pelo contrário, queremos marcar o grande fardo que carrega a pessoa que se empreende por esse caminho, pois, ao traduzir obras que carregam consigo sentidos muitas vezes específicos, como são as grandes obras filosóficas, literárias e poéticas, já sempre se faz uma interpretação destas para se decidir pelo uso de uma ou outra expressão. Por esse motivo, mais importante que se ater a terminologias e traduções, é necessário compreender o pensamento que tais termos querem transmitir.

Para finalizar, acreditamos que é de fundamental importância pensar a obra heideggeriana em português, uma vez que é possível e necessário se fazer filosofia em nossa língua e pensar as traduções, como indicamos diversas vezes ao decorrer do trabalho, é, antes de tudo, pensar o sentido filosófico.

\section{Referências}

HEIDEGGER, M. El ser y el tempo. Tradução de José Gaos. México, D.F.: Fondo de Cultura Económica, 1951. 
Being and time. Tradução de John Macquarrie e Edward Robinson. Oxford, UK: Blackwell Publishers, 1962.

Sein und Zeit. In: Gesamtausgabe Band 2. Framkfurt am Main: Vittorio Klostermann, 1977.

Os conceitos fundamentais da metafísica: mundo, finitude, solidão. Tradução de Marco Antônio Casanova. 2. ed. - Rio de Janeiro: Forense Universitária, 2011.

Ser e tempo. Tradução de Fausto Castilho. Campinas, SP: Editora da Unicamp; Petrópolis, RJ: Vozes, 2012. (Edição bilíngue português-alemão).

Ser e tempo. Tradução de Márcia Sá Cavalcante. 10. ed. Petrópolis, RJ: Vozes; Bragança Paulista, SP: Editora Universitária São Francisco, 2015.

BORGES-DUARTE, I. O afecto na Análise Existencial heideggeriana. In: CASANOVA, M. A.; ESTRADA, P. C. D. Fenomenologia Hoje V. Fenomenologia e Filosofia Prática. Atas do V Congresso Luso-Brasileiro de Fenomenologia. Rio de Janeiro, Via Verita, 2015. p. 3-19. Disponível em: http://dspace.uevora.pt/rdpc/handle/10174/18116 Acesso em: 28 de jun. de 2018.

CASANOVA, M. A. Compreender Heidegger. 5 ed. Petrópolis, RJ: Vozes, 2015.

. Mundo e historicidade: leituras fenomenológicas de Ser e tempo - Volume 1 Existência e mundaneidade. Rio de Janeiro: Via Verita, 2017.

. Notas do tradutor. In. HEIDEGGER, M. Os conceitos fundamentais da metafísica: mundo, finitude e solidão. Tradução de Marco Antonio Casanova. Rio de Janeiro: Forense Universitária, 2011.

ELPIDOROU, A; FREEMAN, L. Affectivity in Heidegger I: moods and emotions in Being and time. In: Philosophy Compass. v. 10. 2015. p. 661-671. Disponível em: https://www.researchgate.net/publication/280134255_Affectivity_in_Heidegger_I_Moods_a nd_Emotions_in_Being_and_Time Acesso em: 17 de set. de 2018.

GREISCH, J. Ontologie et temporalité: Esquisse d'une interprétation intégrale de Sein und Zeit. Paris: Presses Universitaires de France, 1994.

INWOOD, M. Dicionário Heidegger. Tradução de Luísa Buarque de Holanda; revisão técnica de Márcia Sá Cavalcante Schuback. Rio de Janeiro: Jorge Zahar Editora, 2002.

KOECHER, J. Heidegger's concept of Stimmung and its relevance to the practice of psychotherapy. In: Existential Analysis. v. 24. n. 2. 2013. p. 263-267. Disponível em: http://go.galegroup.com/ps/anonymous?id=GALE\%7CA346627557\&sid=googleScholar\&v=2. $1 \& i t=r \& l i n k a c c e s s=a b s \& i s s n=17525616 \& p=A O N E \& s w=w$ Acesso em: 17 de set. de 2018 .

XOLOCOTZI, Á. Introducción. In: Studia Heideggeriana. v. 4. 2015. p. 9-20.

Submissão: 31.10.2018 / Aceite: 30.11.2018. 